\title{
Association of retinal arteriolar dilatation with lower verbal memory: the Edinburgh Type 2 Diabetes Study
}

\author{
J. Ding • M. W. J. Strachan • F. G. R. Fowkes • \\ T. Y. Wong • T. J. MacGillivray • N. Patton • \\ T. A. Gardiner • I. J. Deary • J. F. Price
}

Received: 20 December 2010 / Accepted: 2 March 2011/Published online: 1 April 2011

(C) Springer-Verlag 2011

\begin{abstract}
Aims/hypothesis Retinal vascular calibre changes may reflect early subclinical microvascular disease in diabetes. Because of the considerable homology between retinal and cerebral microcirculation, we examined whether retinal vascular calibre, as a proxy of cerebral microvascular disease, was associated with cognitive function in older people with type 2 diabetes.

Methods A cross-sectional analysis of 954 people aged 60 75 years with type 2 diabetes from the population-based Edinburgh Type 2 Diabetes Study was performed. Participants underwent standard seven-field binocular digital retinal photography and a battery of seven cognitive function tests. The Mill Hill Vocabulary Scale was used to estimate pre-morbid cognitive ability. Retinal vascular calibre was measured from an image field with the optic disc in the centre using a validated computer-based program.
\end{abstract}

J. Ding $(\bowtie) \cdot$ F. G. R. Fowkes · J. F. Price

Centre for Population Health Sciences,

University of Edinburgh,

Teviot Place,

Edinburgh EH8 9AG, UK

e-mail: J.Ding_2@yahoo.co.uk

M. W. J. Strachan

Metabolic Unit, Western General Hospital,

Edinburgh, UK

T. Y. Wong

Singapore Eye Research Institute, Singapore National Eye Centre,

Singapore, Republic of Singapore

T. J. MacGillivray

Clinical Research Facility, Western General Hospital,

Edinburgh, UK
Results After age and sex adjustment, larger retinal arteriolar and venular calibres were significantly associated with lower scores for the Wechsler Logical Memory test, with standardised regression coefficients -0.119 and -0.084 , respectively $(p<0.01)$, but not with other cognitive tests. There was a significant interaction between sex and retinal vascular calibre for logical memory. In male participants, the association of increased retinal arteriolar calibre with logical memory persisted $(p<0.05)$ when further adjusted for vocabulary, venular calibre, depression, cardiovascular risk factors and macrovascular disease. In female participants, this association was weaker and not significant.

Conclusions/interpretation Retinal arteriolar dilatation was associated with poorer memory, independent of estimated prior cognitive ability in older men with type 2 diabetes. The sex interaction with stronger findings in men requires confirmation. Nevertheless, these data suggest that impaired cerebral arteriolar autoregulation in smooth muscle cells,

N. Patton

The Manchester Centre for Vision,

Manchester Royal Eye Hospital,

Manchester, UK

T. A. Gardiner

Centre for Biomedical Science Education,

Queen's University Belfast,

Belfast, UK

I. J. Deary

Department of Psychology, University of Edinburgh,

Edinburgh, UK

I. J. Deary $\cdot$ J. F. Price

Centre for Cognitive Ageing and Cognitive Epidemiology,

University of Edinburgh,

Edinburgh, UK 
leading to arteriolar dilatation, may be a possible pathogenic mechanism in verbal declarative memory decrements in people with diabetes.

Keywords Memory $\cdot$ Retinal vascular calibre .

Type 2 diabetes

$\begin{array}{ll}\text { Abbreviations } \\ \text { CRAE } & \text { Central retinal arteriole equivalent } \\ \text { CRVE } & \text { Central retinal venule equivalent } \\ \text { DST } & \text { Digit Symbol Test } \\ \text { ET2DS } & \text { Edinburgh Type 2 Diabetes Study } \\ \text { ETDRS } & \text { Early Treatment Diabetic Retinopathy Study } \\ \text { FACES } & \text { Faces and Family Pictures Subtest } \\ \text { LM test } & \text { Logical Memory test } \\ \text { LNS } & \text { Letter-number sequencing } \\ \text { MI } & \text { Myocardial infarction } \\ \text { MR } & \text { Matrix reasoning } \\ \text { MHVS } & \text { Mill Hill Vocabulary Scale } \\ \text { MMSE } & \text { Mini Mental State Examination } \\ \text { TIA } & \text { Transient ischaemic attack } \\ \text { TMTB } & \text { Trail Making Test-Part B } \\ \text { VFT } & \text { Borkowski Verbal Fluency Test }\end{array}$

\section{Introduction}

Type 2 diabetes is an established risk factor for cognitive impairment and dementia [1,2]. As yet, it is unclear which factors mediate the accelerated cognitive ageing in people with type 2 diabetes, although cerebral microvascular disease may be important [3-5]. The cerebral microvascular circulation is, however, difficult to evaluate in detail in humans using current neuroimaging methods.

The retinal vessels provide a unique window on cerebral vascular status, given the shared embryological, anatomical and physiological characteristics between retinal and cerebral microvasculature $[6,7]$. The retinal vascular bed can be directly visualised non-invasively with retinal photography. Some previous studies [8], including the cohort studied here [9], have shown a significant association between diabetic retinopathy signs (e.g. microaneurysms, retinal haemorrhages) and reduced cognitive performance in people with diabetes and in the general population. Computer-assisted quantitative measurement of retinal vascular calibre has recently been introduced and has proved to be accurate and reliable [10]. There is increasing experimental and epidemiological evidence that changes in retinal vascular calibre may be a biomarker of early microvascular dysfunction (i.e. before the classical signs of diabetic retinopathy are evident) associated with diabetes and other cerebral vascular diseases, including stroke [11-
16]. Despite a potential link, few studies have investigated the association between retinal vascular calibre and cognitive function. In the general population, one study [17] reported that retinal venular dilatation, but not arteriolar calibre, was associated with cognitive impairment in people with hypertension, whereas others found no associations [18-21]. To our knowledge, however, the association between retinal vascular calibre and cognition has not been explored in people with type 2 diabetes. Our hypothesis is that a better understanding of the association between cognitive abilities in people with type 2 diabetes and retinal vascular calibre, potentially reflecting lifetime cumulative effects of chronic hyperglycaemia on the microvasculature, may offer insights into the contribution of early microvascular disease in the brain to the development of accelerated cognitive impairment in diabetes. It is hoped that such insights, when added to an increasing body of research on other potential causes of cognitive decrements in type 2 diabetes, will lead to the development of novel preventive approaches aimed at reducing cognitive decline in this at-risk population.

The aim of this study was to examine the relationship between retinal vessel calibre and cognitive function using cross-sectional data from a large, well-characterised sample of older men and women with type 2 diabetes. Cognitive function was measured using a detailed battery of neuropsychological tests assessing major cognitive domains. Retinal vascular calibre was measured using validated computer-assisted techniques.

\section{Methods}

Study population The Edinburgh Type 2 Diabetes Study (ET2DS) is an ongoing population-based cohort study investigating potentially modifiable risk factors for cognitive decrements in people with type 2 diabetes. The study began in $2006 / 2007$ as a cross-sectional survey of 1,066 men and women aged 60-75 years with type 2 diabetes living in Lothian, Scotland, UK. Ethical approval for the ET2DS was granted by the Lothian Research Ethics Committee, and written informed consent was obtained from all participants. Details of the study recruitment and examination procedures have been published [22].

Of the 1,066 participants who underwent cognitive and physiological testing, we excluded 30 with a Mini Mental State Examination (MMSE) score of $<24$, indicating possible pathological cognitive impairment. Of the remaining 1,036 participants, 21 had no retinal photographs and a further 61 did not have gradable photographs of sufficient quality in either eye for measuring vessel calibre, leaving 954 who provided data for this analysis. 
Cognitive assessment Specially trained research assistants (trained and then observed for validation by one expert in psychological testing: IJD) administered a detailed battery of cognitive tests in a standard order during a single session in a quiet and well-lit room, following tests for adequate visual acuity and capillary blood glucose levels $(>4.0 \mathrm{mmol} / \mathrm{l})$.

Major domains of cognitive ability were assessed using tests of immediate and delayed non-verbal memory and verbal declarative memory (Faces and Family Pictures Subtest [FACES], Logical Memory subtest [LM test] from the Wechsler Memory Scale-III UK [23]); non-verbal reasoning, working memory, information processing speed (matrix reasoning [MR], letter-number sequencing [LNS], Digit Symbol Test [DST] from the Wechsler Adult Intelligence Scale 3rd Edition [WAIS-III UK] [24]); executive function (Borkowski Verbal Fluency Test [VFT] [25]); and mental flexibility (Trail Making Test-Part B [TMTB] [26]). The FACES test comprises a series of pictures of faces that are shown to participants and then, in subsequent immediate and delayed tests, participants are asked to select these faces from a larger series of pictures. The test is scored as the number of correct responses. The LM test involves the immediate recall of a short story containing 25 memory items, which is read aloud to the participant. Participants are informed that they will be questioned about the story again later, and delayed recall is recorded in the same way after approximately $40 \mathrm{~min}$. The test is scored as the number of memory items recalled correctly. Given the high correlation between the immediate and delayed sub-components of the FACES task $(r=0.55)$, these were summed to form a single score. A similar approach was taken for the immediate and delayed recall sub-components of the LM test $(r=0.87)$, giving an overall score for logical memory. The MR test involves inspecting a pattern arrayed in matrix form with a piece missing. The elements of the matrix are logically constructed. The task is to select the correct missing piece from the answer options. The LNS test involves listening to jumbled strings of numbers and letters and recounting these with the numbers first in numerical order, and then the letters in alphabetical order. The DST involves entering symbols as quickly as possible according to a given code, and is scored as the number of symbols matched correctly to their corresponding numbers in 120 seconds. The VFT involves vocally generating as many words as possible that begin with a given letter $(\mathrm{C}, \mathrm{F}$ and $\mathrm{L})$, within a one minute period for each letter. The score for this test is the total number of acceptable words stated. The TMTB involves drawing a line between numbers and letters in an alternating order and in as short a time as possible. The test is scored as the time (in seconds) it takes to complete Part B. All of these are fluid-type mental tests, which are sensitive to ageing effects.
Vocabulary ('crystallised' intelligence) was measured using the combined version of the Junior and Senior Mill Hill Vocabulary Scale (MHVS) synonyms [27]. As results on vocabulary-based tests tend to decline little with ageing, they can be used to estimate peak prior cognitive ability [28, 29]. The MMSE is often used in screening for dementia, and was included as a general mental assessment for possible cognitive pathology [30]. Degree of depressed mood was assessed using the Hospital Anxiety and Depression Scale and only the depression items were scored [31].

Retinal photography and grading After pupillary dilatation, standard seven-field non-stereoscopic colour photographs were taken of both eyes at $35^{\circ}$ using a high resolution digital retinal camera. Retinal vessel calibre was measured on the image centred on the optic disc using a custom-written validated image analysis program (within MatLab: Mathworks, Natick, MA, USA). Each image was processed and converted to greyscale prior to analysis. A single trained grader (JD), blind to other clinical and cognitive features, performed the vessel measurements in one randomly selected eye (computer generated random number) or the eye with best image quality. Left and right eye vessel calibre measurements are highly correlated [32]. The six largest arterioles and venules coursing through a zone between 0.5 and 1 disc diameter away from the optic disc edge were measured using a microdensitometric technique [33]. Estimates were summarised as central retinal arteriole equivalent (CRAE) using a formula which accounts for asymmetry of branching arterioles [33], and central retinal venule equivalent (CRVE) using a revised Knudtson-Parr-Hubbard formula [34]. The intragrader reliability was assessed (10 weeks apart) in a randomly selected sample of 20 images; the intraclass correlation coefficient was 0.74 for CRAE and 0.95 for CRVE. To aid comparison with other studies, the pixel measurements from the image were converted to $\mu \mathrm{m}$ based on an assumption of the average optic disc diameter (approximately 327 pixels in our cohort) being equal to $1,850 \mu \mathrm{m}[10]$.

Measurement of other variables Participants completed a detailed questionnaire on socio-demographic characteristics, lifestyle variables, medication use and medical history of diabetes and cardiovascular disease (including the WHO chest pain questionnaire [35]), and underwent standardised clinical examinations, including measurements of plasma $\mathrm{HbA}_{1 \mathrm{c}}$ and fasting serum total cholesterol and HDLcholesterol, a resting 12-lead ECG and brachial blood pressures [9, 22]. The highest self-reported level of education was categorised as secondary/primary, other professional/technical qualification, or university. Smoking 
status was categorised as current, former or never. Duration of diabetes was estimated by subtracting the year of diagnosis from the date of attendance at the research clinic. Diabetes treatment was classified into three groups: (1) diet control only; (2) oral anti-diabetic agents without insulin; and (3) insulin injection with or without oral agents. WHR was calculated as the waist circumference divided by the hip circumference in $\mathrm{cm}$. Hypertension was defined as systolic blood pressure $\geq 140 \mathrm{mmHg}$ or diastolic blood pressure $\geq 85 \mathrm{mmHg}$ or use of medication prescribed by a doctor to lower blood pressure. Data were collected from the Information and Statistics Division of NHS Scotland on all medical and surgical discharges from Scottish hospitals since 1981 (SMR01 scheme). Any ICD10 (www.who.int/ classifications/icd/en/) or ICD9 (www.icd9data.com/2007/ Volume1/240-279/250-259/250/default.htm) codes for cardiovascular or cerebrovascular disease were extracted and used together with self-reported vascular disease details and findings from the chest pain questionnaire and ECG (in addition to a review of clinical notes where required) to define myocardial infarction (MI), angina, stroke and transient ischaemic attack (TIA), according to pre-defined criteria [9]. Intermittent claudication was based on a positive response to the Edinburgh Claudication Questionnaire [36]. Any macrovascular disease was defined as a history of MI, angina, stroke, TIA or peripheral arterial disease. Assessment of diabetic retinopathy from 7-field photographs was based on the scale described by the Early Treatment Diabetic Retinopathy Study (ETDRS) research group [37]. Diabetic retinopathy was defined as an ETDRS level of 20 and greater [9].

Statistical analyses All continuous variables were normally distributed apart from the TMTB (for which a base $e$ logarithmic transformation of scores was used), depression scores (normalised through an $n+1$ logarithmic transformation) and duration of diabetes (square root transformation). Linear regression was used to model retinal vascular calibre against cognitive ability scores. The modelling approach used a four-tiered process. Initially, age and sex were controlled for. Further adjustment was made for peak prior cognitive ability as estimated by MHVS followed by additional inclusion of traditional systemic risk factors, which consisted of education level, cardiovascular risk factors (smoking status, systolic blood pressure, the presence of macrovascular disease) and depression symptoms. These variables were selected as possible confounders if they showed a significant association with retinal vascular calibre on univariate analysis or if, in previous literature, a variable was reported to be associated with both retinal vascular calibre and cognitive test performance. We did not include duration of diabetes and $\mathrm{HbA}_{1 \mathrm{c}}$ in the main multivariate model because it is likely that prolonged exposure to hyperglycaemia underlies the change in retinal vessel calibre and their inclusion in the model could result in overadjustment. Finally, the fellow vessel calibre (i.e. inclusion of venular calibre in models for arteriolar calibre and vice versa) was added to the multivariate model including the other as a covariable, to examine whether both contributed separately to variance in cognitive performance. This was done because CRAE and CRVE were highly correlated $(r=0.61, p<0.01)$ and may share common genetic and other influences [38]. Variable collinearity was checked by using tolerance and variance inflation, and standardised residual plots were also inspected. Interactions between vessel calibre and other covariates were assessed with respect to effects on cognition. All tests were two-tailed and a $p$ value $\leq 0.05$ was taken to indicate statistical significance. However, given that many statistical tests were performed (e.g. there were two retinal calibre indices and each was studied with regard to associations with seven cognitive variables), the prudent approach here was to acknowledge that very low $p$ values were more likely to indicate replicable associations [39]. We are aware of the multiple testing issue, but considered that statistical adjustment (e.g. Bonferroni corrections) would be over-stringent in this situation given that the cognitive test variables were not independent and that we were properly cautious in relation to the multiple tests. All analyses were performed using SPSS 14.0 for Windows [40].

\section{Results}

Characteristics of the total ET2DS population and comparisons with nonparticipants from the target population have been reported previously [41]. A total of 954 participants had retinal photographs available for vessel calibre grading. These participants did not differ significantly from participants without vessel calibre measurement $(n=82)$ with respect to diabetes duration or treatment, mean $\mathrm{HbA}_{1 \mathrm{c}}$, cardiovascular risk factor profile, or history of macrovascular disease and diabetic retinopathy (data not shown). However, they did perform significantly better on tests of non-verbal memory (mean \pm SD FACES scores $66.3 \pm 7.8$ vs $61.9 \pm 7.4$; $p<0.001$ ), mental flexibility (geometric mean TMTB time $105.6 \pm 1.5 \mathrm{~s}$ vs $124.0 \pm 1.6 \mathrm{~s} ; p<0.001)$ and information processing speed (mean DST scores $50.1 \pm 14.5$ vs $45.5 \pm$ 13.6; $p=0.007$ ). A summary of the study participants is presented in Table 1 . The mean values for CRAE were $167.5 \pm 24.7$ and $227.8 \pm 35.7 \mu \mathrm{m}$ for CRVE. There were no significant sex differences on retinal vessel calibre measures. 
Table 1 Characteristics and clinical features of the ET2DS participants $(n=954)$

\begin{tabular}{|c|c|c|c|}
\hline Variable & Total & Women & Men \\
\hline Age (years) & $67.2 \pm 4.20$ & $67.0 \pm 4.3$ & $67.5 \pm 4.1$ \\
\hline Men & $486(50.9)$ & - & - \\
\hline \multicolumn{4}{|l|}{ Education level } \\
\hline University & $158(16.6)$ & $69(14.7)$ & $89(18.3)$ \\
\hline Other profession/technical qualification & $280(29.4)$ & $133(28.4)$ & $147(30.2)$ \\
\hline Secondary/primary school & $516(54.1)$ & $266(56.8)$ & $250(51.4)$ \\
\hline Diabetes duration (years) & $6.6(3.9-11.2)$ & $6.4(3.7-10.4)$ & $6.9(4.1-11.9)$ \\
\hline $\mathrm{HbA}_{1 \mathrm{c}}(\%)$ & $7.4 \pm 1.10$ & $7.4 \pm 1.10$ & $7.4 \pm 1.10$ \\
\hline Insulin treatment & $166(17.4)$ & $87(18.6)$ & $79(16.3)$ \\
\hline \multicolumn{4}{|l|}{ Smoker } \\
\hline Current & $135(14.2)$ & $59(12.6)$ & $76(15.6)$ \\
\hline Ex-smoker & $451(47.3)$ & $167(35.7)$ & $284(58.4)$ \\
\hline Never smoked & $368(38.6)$ & $242(51.7)$ & $126(25.9)$ \\
\hline WHR & $0.96 \pm 0.08$ & $0.93 \pm 0.07$ & $1.00 \pm 0.06$ \\
\hline Total cholesterol (mmol/l) & $4.3 \pm 0.90$ & $4.5 \pm 0.97$ & $4.2 \pm 0.83$ \\
\hline Systolic blood pressure (mmHg) & $133.0 \pm 16.30$ & $132.6 \pm 16.71$ & $133.4 \pm 15.90$ \\
\hline Diastolic blood pressure $(\mathrm{mmHg})$ & $68.8 \pm 8.91$ & $67.5 \pm 8.77$ & $70.1 \pm 8.86$ \\
\hline Hypertension & $808(84.7)$ & $391(83.5)$ & $417(85.8)$ \\
\hline Stroke and/or TIA & $75(7.9)$ & $23(4.9)$ & $52(10.7)$ \\
\hline Any macrovascular disease (MI, angina, stroke, TIA or IC) & $345(36.2)$ & $130(27.8)$ & $215(44.2)$ \\
\hline HADS depression score & $3(1-6)$ & $3(2-6)$ & $3(1-5)$ \\
\hline Diabetic retinopathy & $317(33.2)$ & $139(29.7)$ & $178(36.6)$ \\
\hline CRAE $(\mu \mathrm{m})$ & $167.5 \pm 24.67$ & $168.5 \pm 24.27$ & $166.5 \pm 25.03$ \\
\hline CRVE $(\mu \mathrm{m})$ & $227.8 \pm 35.72$ & $227.1 \pm 35.45$ & $228.5 \pm 36.01$ \\
\hline VFT & $37.2 \pm 12.63$ & $36.9 \pm 12.61$ & $37.5 \pm 12.66$ \\
\hline FACES & $66.3 \pm 7.76$ & $67.8 \pm 7.80$ & $64.9 \pm 7.40$ \\
\hline TMTB (s) & $102(80-134)$ & $101(78-133)$ & $106(82-135)$ \\
\hline DST & $50.1 \pm 14.51$ & $52.4 \pm 14.83$ & $47.7 \pm 13.81$ \\
\hline MR & $13.1 \pm 5.24$ & $12.3 \pm 5.27$ & $13.9 \pm 5.08$ \\
\hline LM test & $25.5 \pm 8.16$ & $26.3 \pm 8.42$ & $24.8 \pm 7.85$ \\
\hline LNS & $9.8 \pm 2.72$ & $9.7 \pm 2.59$ & $9.9 \pm 2.83$ \\
\hline MHVS & $31.2 \pm 5.08$ & $30.7 \pm 5.07$ & $31.7 \pm 5.04$ \\
\hline
\end{tabular}

Data are means $\pm \mathrm{SD}$, median (interquartile range), or $n(\%)$

HADS, Hospital Anxiety and Depression Scale; IC, intermittent claudication

In the total study population, after adjusting for age and sex, both higher CRAE and CRVE were significantly associated with lower scores for logical memory, with standardised coefficients $-0.119 \quad(p<0.001)$ and -0.084 $(p<0.01)$ (Table 2). Higher CRAE, but not CRVE, was also associated with inferior performance on the DST and estimated peak prior cognitive ability (MHVS) with standardised coefficients $-0.067(p<0.05)$ and $-0.091(p<0.01)$, respectively. No significant associations were found between retinal vessel calibre and other tests of cognitive ability domains. Further adjustment for the MHVS scores reduced the magnitude of the associations while both CRAE and CRVE remained significantly associated with lower logical memory scores with standardised coefficients of $-0.080(p<0.01)$ and $-0.058(p<0.05)$. The associations were retained after additional adjustment for other covariates but became nonsignificant when the fellow vessel calibre was included. However, in the fully adjusted models for logical memory, there was a significant interaction between sex and both CRAE $(p=0.027)$ and CRVE $(p=0.042)$. Men with increased CRAE or CRVE (in the top tertile) appeared to have lower logical memory scores, an effect not seen in women (Fig. 1). The vessel calibre tertiles are shown only for illustration of the interaction, and the whole continuum of the values was assessed in the analyses. 
Table 2 Multivariate associations between retinal vascular calibre (CRAE and CRVE) and late-life cognition

\begin{tabular}{|c|c|c|c|c|c|c|c|}
\hline & VFT & FACES & $-\log _{e}(\mathrm{TMTB})$ & DST & MR & LM & LNS \\
\hline \multicolumn{8}{|l|}{ Variable } \\
\hline \multicolumn{8}{|l|}{ CRAE } \\
\hline Age and sex & $\begin{array}{l}-0.047 \pm \\
0.033\end{array}$ & $\begin{array}{l}0.027 \pm \\
0.030\end{array}$ & $\begin{array}{c}-0.031 \pm \\
0.031\end{array}$ & $\begin{array}{c}-0.067 \pm \\
0.032^{*}\end{array}$ & $\begin{array}{c}-0.027 \pm \\
0.032\end{array}$ & $\begin{array}{l}-0.119 \pm \\
0.033^{* * *}\end{array}$ & $\begin{array}{c}-0.049 \pm \\
0.039\end{array}$ \\
\hline +MHVS & $\begin{array}{c}-0.013 \pm \\
0.028\end{array}$ & $\begin{array}{l}0.056 \pm \\
0.031\end{array}$ & $\begin{array}{c}-0.003 \pm \\
0.040\end{array}$ & $\begin{array}{c}-0.036 \pm \\
0.029\end{array}$ & $\begin{array}{l}0.008 \pm \\
0.024\end{array}$ & $\begin{array}{c}-0.080 \pm \\
0.030^{* *}\end{array}$ & $\begin{array}{c}-0.017 \pm \\
0.026\end{array}$ \\
\hline+ Other variables $^{\mathrm{a}}$ & $\begin{array}{c}-0.007 \pm \\
0.028\end{array}$ & $\begin{array}{l}0.058 \pm \\
0.032\end{array}$ & $\begin{array}{l}0.003 \pm \\
0.040\end{array}$ & $\begin{array}{c}-0.031 \pm \\
0.031\end{array}$ & $\begin{array}{l}0.008 \pm \\
0.024\end{array}$ & $\begin{array}{c}-0.083 \pm \\
0.030^{* *}\end{array}$ & $\begin{array}{c}-0.017 \pm \\
0.026\end{array}$ \\
\hline+ Fellow vessel calibre $^{\mathrm{b}}$ & $\begin{array}{c}-0.025 \pm \\
0.038\end{array}$ & $\begin{array}{l}0.027 \pm \\
0.039\end{array}$ & $\begin{array}{l}0.001 \pm \\
0.043\end{array}$ & $\begin{array}{c}-0.065 \pm \\
0.038\end{array}$ & $\begin{array}{c}-0.005 \pm \\
0.040\end{array}$ & $\begin{array}{c}-0.066 \pm \\
0.039\end{array}$ & $\begin{array}{c}-0.012 \pm \\
0.048\end{array}$ \\
\hline \multicolumn{8}{|l|}{ CRVE } \\
\hline Age and sex & $\begin{array}{c}-0.012 \pm \\
0.033\end{array}$ & $\begin{array}{l}0.037 \pm \\
0.032\end{array}$ & $\begin{array}{c}-0.025 \pm \\
0.025\end{array}$ & $\begin{array}{c}-0.025 \pm \\
0.033\end{array}$ & $\begin{array}{c}-0.013 \pm \\
0.033\end{array}$ & $\begin{array}{c}-0.084 \pm \\
0.031^{* *}\end{array}$ & $\begin{array}{c}-0.034 \pm \\
0.023\end{array}$ \\
\hline +MHVS & $\begin{array}{l}0.008 \pm \\
0.029\end{array}$ & $\begin{array}{l}0.058 \pm \\
0.031\end{array}$ & $\begin{array}{l}0.016 \pm \\
0.016\end{array}$ & $\begin{array}{c}-0.008 \pm \\
0.032\end{array}$ & $\begin{array}{l}0.009 \pm \\
0.036\end{array}$ & $\begin{array}{r}-0.058 \pm \\
0.031^{*}\end{array}$ & $\begin{array}{c}-0.013 \pm \\
0.026\end{array}$ \\
\hline+ Other variables $^{\mathrm{a}}$ & $\begin{array}{l}0.014 \pm \\
0.031\end{array}$ & $\begin{array}{l}0.069 \pm \\
0.032\end{array}$ & $\begin{array}{l}0.004 \pm \\
0.010\end{array}$ & $\begin{array}{l}0.017 \pm \\
0.029\end{array}$ & $\begin{array}{l}0.019 \pm \\
0.025\end{array}$ & $\begin{array}{c}-0.069 \pm \\
0.030^{*}\end{array}$ & $\begin{array}{c}-0.015 \pm \\
0.030\end{array}$ \\
\hline+ Fellow vessel calibre ${ }^{\mathrm{b}}$ & $\begin{array}{l}0.030 \pm \\
0.042\end{array}$ & $\begin{array}{l}0.052 \pm \\
0.043\end{array}$ & $\begin{array}{l}0.003 \pm \\
0.010\end{array}$ & $\begin{array}{l}0.057 \pm \\
0.037\end{array}$ & $\begin{array}{l}0.022 \pm \\
0.042\end{array}$ & $\begin{array}{c}-0.029 \pm \\
0.027\end{array}$ & $\begin{array}{c}-0.008 \pm \\
0.024\end{array}$ \\
\hline
\end{tabular}

Values are standardised $\beta$ coefficient \pm SE

${ }^{a}$ Adjusted for level of education, smoking, systolic blood pressure, major macrovascular disease and depression

${ }^{\mathrm{b}}$ Adjusted for all other variables plus venular calibre (in models of arteriolar calibre) and arteriolar calibre (in models of venular calibre)

* $p<0.05, * * p<0.01, * * * p<0.001$

The population was then stratified by sex, and the association between retinal vessel calibre and logical memory was examined separately for men and women (Table 3). Following age adjustment, significant associations were found only in men for both CRAE and CRVE with standardised coefficients $-0.179(p<0.001)$ and $-0.125(p<0.01)$. Age-adjusted linear regression analyses also showed both higher CRAE and CRVE to be associated with the MHVS in women but not in men, with standardised coefficients of $-0.129(p<0.01)$ and -0.121 $(p<0.05)$ (data not shown). When further adjusted for MHVS and a wide range of potentially confounding variables, including macrovascular disease, associations with logical memory in men remained statistically significant. Additional adjustment for the fellow vessel calibre weakened the magnitude and statistical significance of the associations although the association with CRAE was retained, with a standardised coefficient of -0.127 $(p<0.05)$. No statistically significant associations were found for other tests for either sex (data not shown). There was no significant interaction of retinal vessel calibre and any of the variables other than sex.

When analyses were repeated to exclude individuals with advanced proliferative retinopathy $(n=10)$ in whom vessel calibre can be narrowed due to laser treatment, the overall pattern of associations was similar. After exclusion of those with prevalent stroke or history of TIA $(n=75)$, the association between CRAE and logical memory became less significant $(p=0.070)$ in men. In analyses stratified by hypertension status, the association between CRAE and logical memory was stronger in men with hypertension $(n=417)$, with a standardised coefficient of $-0.136(p<0.05)$, but the association was not present in men without hypertension (data not shown). Finally, inclusion of $\mathrm{HbA}_{1 \mathrm{c}}$ and duration of diabetes in the main models did not essentially change the results (data not shown).

\section{Discussion}

In this representative population of older people with type 2 diabetes, larger retinal arteriolar and venular calibres were both associated with poorer verbal declarative memory as measured using the Wechlser LM test. Significant associations were found only in men. On the other hand, vocabulary score-which is often used to estimate peak prior cognitive ability - was associated with both larger retinal arteriolar and venular calibre in women. The association between retinal arteriolar dilatation and verbal memory in men persisted after additional control for 
a

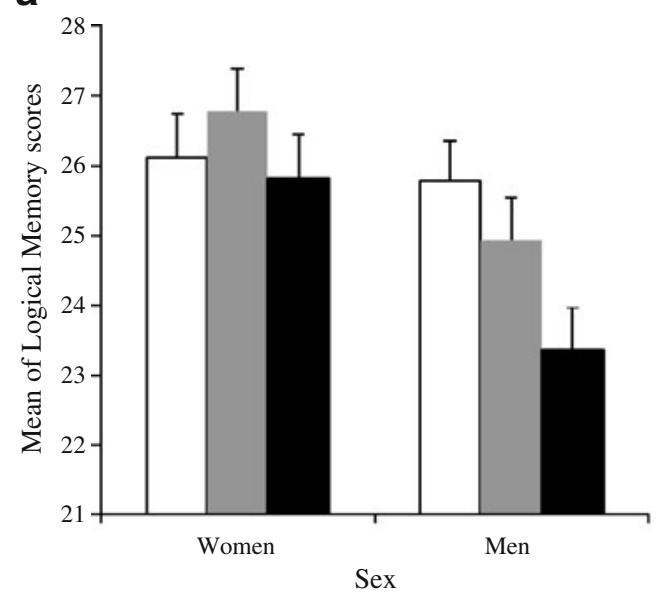

b

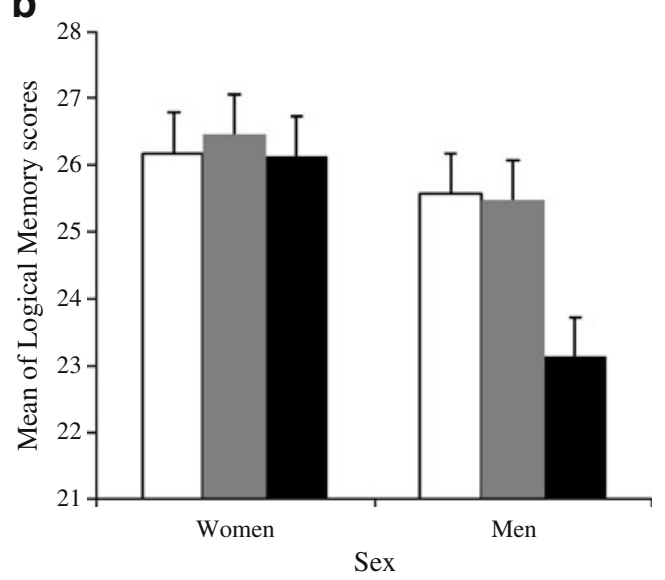

Fig. 1 Mean of logical memory scores according to sex and tertiles of retinal arteriolar (a) and venular (b) calibre. Error bars indicate the standard errors at each point, shown only one side for simplicity. White column, first tertile; grey column, second tertile; black column, third tertile

estimated peak prior cognitive ability, cardiovascular risk factors, macrovascular disease, mood and venular calibre, suggesting that the relationship was not simply due to confounding by other vascular mechanisms.
To our knowledge, the finding of an association between retinal arteriolar dilatation and poorer cognitive functioning on verbal memory has not been previously reported, although one larger population-based study found that retinal venular dilatation was associated with lower MMSE scores [17]. Findings in the ET2DS contrast with the majority of published evidence in the general population, which did not find a significant association between any retinal vessel calibre variables and cognitive test performance [18-21]. A possible reason for the lack of association seen in the general population is that retinal arteriolar dilatation might be a specific indicator of diabetes-related microvascular dysfunction, but not a physiological marker in non-diabetic people.

Arteriolar dilatation is a sign of impaired arteriolar autoregulation in diabetes, which has been suggested to play an important role in the initiation and progression of diabetic retinopathy [13]. This impaired retinal arteriolar constriction could be due to hyperglycaemia and hypoxiamediated endothelin-1 resistance and calcium-influx channel inhibition in smooth muscle cells. Such retinal arteriolar dilatory response could further be exacerbated by a drop in retinal oxygen tension from capillary non-perfusion [13]. In contrast, retinal venular dilatation may represent a later sign of haemodynamic abnormalities, which possibly reflect a direct consequence of arteriolar dysfunction [13].

Given the considerable homology between retinal and cerebral microvasculature, our study may lead to hypothesis about possible underlying mechanisms. Retinal arteriolar dilatation could be a general marker of retinal ischaemia and, by proxy, cerebral ischaemia. It is also possible that retinal arteriolar dilatation reflects concomitant cerebral arteriolar abnormalities in diabetes. As a result, cerebral microvascular disease associated with diabetes may play a role in the episodic memory impairment characteristics of mild cognitive impairment [42]. The ET2DS population comprised older diabetic patients without dementia. Memory is often the first domain of cognition that is affected in

Table 3 Multivariate associations between retinal vascular calibres (CRAE and CRVE) and logical memory in men and women

\begin{tabular}{|c|c|c|c|c|}
\hline \multirow[t]{2}{*}{ Variable } & \multicolumn{2}{|l|}{ Men } & \multicolumn{2}{|l|}{ Women } \\
\hline & CRAE & CRVE & CRAE & CRVE \\
\hline Age & $-0.179 \pm 0.045^{* * *}$ & $-0.125 \pm 0.046^{* *}$ & $-0.061 \pm 0.046$ & $-0.047 \pm 0.047$ \\
\hline +MHVS & $-0.159 \pm 0.041^{* * *}$ & $-0.120 \pm 0.042^{* *}$ & $0.001 \pm 0.018$ & $0.009 \pm 0.045$ \\
\hline+ Other variables ${ }^{\mathrm{a}}$ & $-0.155 \pm 0.045^{* * *}$ & $-0.132 \pm 0.046^{* *}$ & $-0.011 \pm 0.041$ & $0.001 \pm 0.046$ \\
\hline+ Fellow vessel calibre ${ }^{\mathrm{b}}$ & $-0.127 \pm 0.058^{*}$ & $-0.049 \pm 0.061$ & $-0.018 \pm 0.027$ & $0.011 \pm 0.048$ \\
\hline
\end{tabular}

Data are standardised regression coefficients $\pm \mathrm{SE}$

${ }^{a}$ Adjusted for level of education, smoking, systolic blood pressure, major macrovascular disease and depression

${ }^{\mathrm{b}}$ Adjusted for all other variables plus venular calibre (in models of arteriolar calibre) and arteriolar calibre (in models of venular calibre)

${ }^{*} p<0.05,{ }^{* *} p<0.01, * * * p<0.001$ 
participants with mild cognitive impairment, with otherwise relatively preserved cognitive and functional abilities [41]. Memory is not solely dependent on the hippocampus and medial temporal lobe region in the brain, but multiple cortical-subcortical circuits may be involved [42, 43]. Cerebral microvascular disease predominantly affects the subcortical associative areas and may disrupt frontal lobe executive control processes that are critical for working memory (the ability to hold and manipulate information mentally is a component of executive function), which may in turn result in episodic memory (information encoding) deficits [42]. Although a test of working memory was not significant in the present study, a relatively greater degree of variation in verbal memory scores compared with the working memory domain may have increased the sensitivity to detect an association. The FACES test, a measure of non-verbal memory, was not associated with retinal vascular calibre. However, this could be due to a lack of sensitivity in the test [44], and it is therefore possible that our overall finding is a reflection of memory in general, rather than specific to verbal declarative memory, although this could not be ascertained from the data available.

An unexpected finding of the present study was a significant interaction of retinal vessel calibre with sex, such that the negative associations were statistically significant only in men. This difference was not anticipated a priori and the reasons for the observations are not apparent. It is possible that other unknown risk factors that were not examined in this analysis, such as oestrogen use, could play a mediating role. It is also possible that measurements from one eye in women are more influenced by measurement error, and such non-differential error would have tended to dilute associations toward the null. Despite a high correlation between eyes, which would indicate that the measurement of retinal vessel calibre in one eye could be adequate for studies evaluating the systemic associations of retinal vascular calibre, there is a potential for loss of statistical power to detect such associations, because of the lower precision in vessel calibre data compared with averaged measurements in two eyes. In particular, women have poorer correlations in retinal vessel calibre measurements between eyes than men [45]. These differences may reflect greater variability of measurement in women, as a result of variations in biological and physiological factors. Alternatively, in women, given that both retinal arteriolar and venular dilatations in later life were associated with peak prior cognitive ability but not current cognitive measures, the possibility of a reverse causation cannot be ruled out. Nevertheless, the interaction between sex and retinal vessel calibre should be interpreted with caution until it has been replicated in other large studies.
The association between larger retinal arteriolar calibre and verbal memory became less significant after participants with recognised clinical stroke were excluded. However, it is uncertain whether this is due to lack of statistical power or whether stroke could play an intermediate role in the same pathway leading to cognitive dysfunction. The presence of stroke may also represent more severe microvascular disease, given that people with type 2 diabetes are particularly prone to ischaemic strokes of microvascular origin [46]. Excluding this type of stroke (which is more likely to cause greater variation in retinal vessel calibre and cognitive impairment) might have led to the observed association towards the null.

The main strengths of the study include the use of quantitative methods to measure retinal vessel calibre in high quality digital photographs, the application of a detailed cognitive test battery covering major cognitive domains, and a large population-based sample of older men and women with the full range of severity of type 2 diabetes. In addition, the residual confounding by peak prior mental ability was minimised by controlling for performance on a vocabulary test, rather than relying solely on level of education, as in many previous studies. Extensive phenotyping for potential confounding factors also enabled a comprehensive multivariate analysis. The major limitation of the study is that analyses were cross-sectional, limiting our ability to determine the temporal sequence of the association. The excluded participants, who did not have gradable retinal photographs, performed less well on several tests of cognitive function. Thus, the associations observed may have been attenuated by selective inclusion and restriction of the range of key variables. Measuring only one eye may have diminished the chances of finding significant associations, particularly if the associations are small. Because this was an exploratory study, statistical adjustment for multiple hypothesis testing was not performed and the large number of regression analyses could lead to type 1 errors.

In summary, retinal arteriolar dilatation was associated with poorer verbal memory in older men with type 2 diabetes, independent of peak prior cognitive ability. These findings, particularly the significant relationship seen in men but not women, require further replication and investigation in prospective studies. If confirmed, they could indicate a possible role of impaired cerebral arteriolar autoregulation leading to arteriolar dilatation in the pathogenesis of verbal declarative memory decrements in diabetes. Such insights into the potential mechanisms underlying cognitive decrements in people with diabetes are necessary for informing future research into preventive interventions. 
Acknowledgements This study was supported by a grant from the UK Medical Research Council. We thank staff and participants of the ET2DS and staff at the Wellcome Trust Clinical Research Facility and the Princess Alexandra Eye Pavilion in Edinburgh, where the clinical examinations were performed. J. F. Price and I. J. Deary are members of the University of Edinburgh Centre for Cognitive Ageing and Cognitive Epidemiology, part of the cross council Lifelong Health and Wellbeing Initiative, which is funded by the BBSRC, EPSRC, ESRC and MRC.

Duality of interest The authors declare that there is no duality of interest associated with this manuscript.

\section{References}

1. Cukierman T, Gerstein HAC, Williamson JD (2005) Cognitive decline and dementia in diabetes - systematic overview of prospective observational studies. Diabetologia 48:2460-2469

2. Biessels GJ, Staekenborg S, Brunner E, Brayne C, Scheltens P (2006) Risk of dementia in diabetes mellitus: a systematic review. Lancet Neurol 5:64-74

3. Starr JM, Wardlaw J, Ferguson K, MacLullich A, Deary IJ, Marshall I (2003) Increased blood-brain barrier permeability in type 2 diabetes demonstrated by gadolinium magnetic resonance imaging. J Neurol Neurosurg Psychiatry 74:70-76

4. Manschot SM, Brands AM, van der Grond J et al (2006) Brain magnetic resonance imaging correlates of impaired cognition in patients with type 2 diabetes. Diabetes 55:1106-1113

5. van Harten B, Oosterman J, Muslimovic D, van Loon BJ, Scheltens P, Weinstein HC (2007) Cognitive impairment and MRI correlates in the elderly patients with type 2 diabetes mellitus. Age Ageing 36:164-170

6. Patton N, Aslam T, Macgillivray T, Pattie A, Deary IJ, Dhillon B (2005) Retinal vascular image analysis as a potential screening tool for cerebrovascular disease: a rationale based on homology between cerebral and retinal microvasculatures. J Anat 206:319348

7. Kwa VI, van der Sande JJ, Stam J, Tijmes N, Vrooland JL (2002) Retinal arterial changes correlate with cerebral small-vessel disease. Neurology 59:1536-1540

8. Ding J, Patton N, Deary IJ et al (2008) Retinal microvascular abnormalities and cognitive dysfunction: a systematic review. $\mathrm{Br} \mathrm{J}$ Ophthalmol 92:1017-1025

9. Ding J, Strachan MW, Reynolds RM et al (2010) Diabetic retinopathy and cognitive decline in older people with type 2 diabetes: the Edinburgh Type 2 Diabetes Study. Diabetes 59:2883-2889

10. Hubbard LD, Brothers RJ, King WN et al (1999) Methods for evaluation of retinal microvascular abnormalities associated with hypertension/sclerosis in the Atherosclerosis Risk in Communities Study. Ophthalmology 106:2269-2280

11. Klein R, Klein BE, Moss SE et al (2004) The relation of retinal vessel calibre to the incidence and progression of diabetic retinopathy: XIX the Wisconsin Epidemiologic Study of Diabetic retinopathy. Arch Ophthalmol 122:76-83

12. Alibrahim E, Donaghue KC, Rogers S et al (2006) Retinal vascular caliber and risk of retinopathy in young patients with type 1 diabetes. Ophthalmology 113:1499-1503

13. Gardiner TA, Archer DB, Curtis TM, Stitt AW (2007) Arteriolar involvement in the microvascular lesions of diabetic retinopathy: implications for pathogenesis. Microcirculation 14:25-38

14. Cheung N, Rogers SL, Donaghue KC, Jenkins AJ, Tikellis G, Wong TY (2008) Retinal arteriolar dilation predicts retinopathy in adolescents with type 1 diabetes. Diabetes Care 31:1842-1846
15. Rogers SL, Tikellis G, Cheung N et al (2008) Retinal arteriolar caliber predicts incident retinopathy. The Australian Diabetes, Obesity and Lifestyle (AusDiab) study. Diabetes Care 31:761-763

16. McGeechan K, Liew G, Macaskill P et al (2009) Prediction of incident stroke events based on retinal vessel caliber: a systematic review and individual-participant meta-analysis. Am J Epidemiol 170:1323-1332

17. Liew G, Mitchell P, Wong TY et al (2009) Retinal microvascular signs and cognitive impairment. J Am Geriatr Soc 57:1892-1896

18. Baker ML, Marino Larsen EK, Kuller LH et al (2007) Retinal microvascular signs, cognitive function, and dementia in older persons. Stroke 38:2041-2047

19. Wong TY, Klein R, Sharrett AR et al (2002) Retinal microvascular abnormalities and cognitive impairment in middle-aged persons: the Atherosclerosis Risk in Communities Study. Stroke 33:1487-1492

20. Lesage SR, Mosley TH, Wong TY et al (2009) Retinal microvascular abnormalities and cognitive decline. The ARIC 14-year follow-up study. Neurology 73:862-868

21. Patton N, Pattie A, MacGillivray T et al (2007) The association between retinal vascular network geometry and cognitive ability in an elderly population. Invest Ophthalmol Vis Sci 48:1995-2000

22. Price JF, Reynolds RM, Mitchell RJ et al (2008) The Edinburgh Type 2 Diabetes Study: study protocol. BMC Endocr Disord 8:18-28

23. Wechsler D (1987) Manual of the Wechsler memory scalerevised. Psychological Corporation, New York

24. Wechsler D (1998) Wechsler adult intelligence scale (UK), 3rd edn. Psychological Corporation, London

25. Lezak M (1995) Neuropsychological assessment, 3rd edn. Oxford University Press, Oxford

26. Spreen O, Strauss E (1991) A compendium of neuropsychological tests: administration, norms, and commentary. Oxford University Press, New York

27. Raven J, Raven JC, Court JH (1998) Manual for Raven's progressive matrices and vocabulary scales. Oxford Psychologists Press, Oxford

28. Salthouse TA (2004) Localizing age-related individual differences in a hierarchical structure. Intelligence 32:541-561

29. Deary IJ, Whalley LJ, Crawford JR (2004) An 'instantaneous' estimate of a lifetime's cognitive change. Intelligence 32:113-119

30. Folstein MF, Folstein SE (1975) Mini mental state. A practical method for grading the cognitive state of patients for the clinician. J Psychiat Res 12:189-198

31. Zigmond AS, Snaith RP (1983) The hospital anxiety and depression scales. Acta Psychiatr Scand 67:361-370

32. Wong TY, Knudtson MD, Klein R, Klein BE, Meuer SM, Hubbard LD (2004) Computer-assisted measurement of retinal vessel diameters in the Beaver Dam Eye Study: methodology, correlation between eyes, and effect of refractive errors. Ophthalmology 111:1183-1190

33. Patton N, Aslam T, Macgillivray T, Dhillon B, Constable I (2006) Asymmetry of retinal arteriolar branch widths at junctions affects ability of formulae to predict trunk arteriolar widths. Invest Ophthalmol Vis Sci 47:1329-1333

34. Knudtson MD, Lee KE, Hubbard LD, Wong TY, Klein R, Klein BE (2003) Revised formulas for summarizing retinal vessel diameters. Curr Eye Res 27:143-149

35. Rose G, McCartney P, Reid DD (1977) Self-administration of a questionnaire on chest pain and intermittent claudication. $\mathrm{Br} \mathrm{J}$ Prev Soc Med 31:42-48

36. Leng GC, Fowkes FG (1992) The Edinburgh Claudication Questionnaire: an improved version of the WHO/Rose Questionnaire for use in epidemiological surveys. J Clin Epidemiol 45:1101-1109

37. Early Treatment Diabetic Retinopathy Study Research Group (1991) Grading diabetic retinopathy from stereoscopic color 
fundus photographs: an extension of the modified Airlie House classification. ETDRS Report Number 10. Ophthalmology 98:786-806

38. Liew G, Sharrett AR, Kronmal R et al (2007) Measurement of retinal vascular caliber: issues and alternatives to using the arteriole to venule ratio. Invest Ophthalmol Vis Sci 48:52-57

39. Deary IJ, Bastin ME, Pattie A et al (2006) White matter integrity and cognition in childhood and old age. Neurology 66:505-512

40. SPSS for Windows (2004) SPSS Inc, Chicago

41. Marioni RE, Strachan MW, Reynolds RM et al (2010) Association between raised inflammatory markers and cognitive decline in elderly people with type 2 diabetes: the Edinburgh Type 2 Diabetes Study. Diabetes 59:710-713
42. Nordahl CW, Ranganath C, Yonelinas AP, DeCarli C, Reed BR, Jagust WJ (2005) Different mechanisms of episodic memory failure in mild cognitive impairment. Neuropsychologia 43:16881697

43. Buffon F, Porcher R, Hernandez K et al (2006) Cognitive profile in CADASIL. J Neurol Neurosurg Psychiatry 77:175-180

44. Strauss E, Sherman EMS, Spreen O (2006) A compendium of neuropsychological tests: administration, norms, and commentary, 3rd edn. Oxford University Press, New York

45. Wong TY, Klein R, Sharrett AR et al (2004) Retinal arteriolar diameter and risk for hypertension. Ann Intern Med 17:248-255

46. Sander D, Sander K, Poppert H (2008) Review: stroke in type 2 diabetes. Br J Diabetes Vasc Dis 8:222-229 